\title{
Feeding Competition and Agonistic Relationships Among Bwindi Gorilla beringei
}

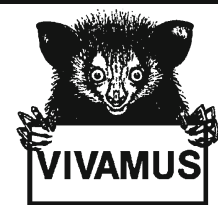

\author{
Martha M. Robbins
}

Received: 13 April 2007 / Accepted: 16 November 2007 /

Published online: 7 August 2008

(C) The Author(s) 2008

\begin{abstract}
Testing predictions of socioecological models, specifically that the types of feeding competition and social relationships female primates exhibit are strongly influenced by the distribution, density, and quality of food resources, requires studies of closely related populations of subjects living under different ecological conditions. I examined feeding competition and the resulting female social relationships in mountain gorillas (Gorilla beringei beringei) of Bwindi Impenetrable National Park, Uganda, which has ecological conditions distinctive from those where other gorilla populations live. I observed 1 group of gorillas for 29 mo to examine the proportion of time spent foraging on fruit, the relationship between patch size and occupancy patterns of fruit trees, and agonistic interactions. Patch occupancy time while foraging in fruit trees decreased with increasing number of gorillas in a tree and decreasing tree size, suggesting that fruit trees represent limiting patches and can lead to intragroup scramble competition. Gorillas exhibited higher levels of aggression while feeding on fruit versus other food resources, which indicates intragroup contest competition. I observed a linear dominance hierarchy with no bidirectionality via displacements, and a similar hierarchy via aggression, though a notable proportion of the dyads contained 2-way interactions. However, most aggression was of low intensity (vocalizations) and the recipient typically ignored it. Despite differences in ecological conditions and diet between the Virunga Volcanoes and Bwindi, agonistic relationships among females are largely similar in the 2 populations and are best characterized as dispersal individualistic.
\end{abstract}

Keywords dominance rank · feeding competition · mountain gorilla · social relationships

M. M. Robbins $(\square)$

Max Planck Institute for Evolutionary Anthropology,

04103 Leipzig, Germany

e-mail: robbins@eva.mpg.de 


\section{Introduction}

A major premise of socioecological models is that the distribution, density, and quality of food resources has an impact on the competitive interactions among female group members of diurnal primates, which in turn influences the type of female social relationships exhibited (Isbell and Young 2002; Koenig 2002; Sterck et al. 1997; van Schaik 1989; Wrangham 1980). In particular, the model predicts that if resources are available in large patches or are evenly distributed, intragroup competition will be predominantly of the scramble type. As resources become limited with an increase in group size, all members will experience a decrease in net energy gain and potentially reduced reproductive success. They will gain little by forming dominance relationships or alliances with kin, or by being philopatric, so that the resulting relationships among females are dispersal-egalitarian (Sterck et al. 1997). If food resources occur in high-quality defendable patches that cannot accommodate all group members, the model predicts that contest competition may result such that dominance hierarchies emerge, coalitions with kin and philopatry become beneficial, and resident-nepotistic relationships exist among females (Sterck et al. 1997). As individuals increase foraging time on defendable patches, the level of feeding competition should increase. Correspondingly, dominance hierarchies should become more pronounced. In addition, intergroup competition may affect social relationships, but the difficulties of measuring it have made testing such predictions problematic.

One approach to testing the predictions of the socioecological model is to examine changes in particular behavior, including agonistic interactions and spatial patterns, as social groups forage on resources of differently sized patches. Leighton and Leighton (1982), Stevenson et al. (1998), Strier (1989), Vogel (2005), and White and Wrangham (1988) showed that the size of food patches can limit the number of individuals foraging within them, and components of patch occupancy may serve as indicators of intragroup scramble competition (Snaith and Chapman 2005). Individuals may also show higher rates of aggression when feeding on highly clumped resources (Barton and Whitten 1993; Koenig et al. 1998; Pazol and Cords 2005; Pruetz and Isbell 2000; Range and Noë 2002; Saito 1996; Wittig and Boesch 2003), which would reflect intragroup contest competition. Higher-ranking individuals should have preferential access to limiting resources, greater net energy gains, and higher reproductive success than lower-ranking group members would (Janson and van Schaik 1988; Koenig 2002; Sterck et al. 1997; Whitten 1983).

A second approach to testing the socioecological model is to compare populations of the same species or closely related species occurring in differing ecological conditions. Studies of baboons (Barton et al. 1996), langurs (Koenig 2000; Koenig et al. 1998), and squirrel monkeys (Boinski et al. 2002; Mitchell et al. 1991) strongly support the model. In addition, studies of sympatric species have shown that differences in female social relationships are largely due to differences in the size, distribution, and quality of food patches (Isbell and Pruetz 1998; Isbell et al. 1998; Pruetz and Isbell 2000; Sterck and Steenbeck 1997).

Gorillas live in a wide range of ecological conditions across central Africa, exhibit wide variability in their dietary habits, and therefore represent a useful genus to test the socioecological model (Doran and McNeilage 1998, 2001; Robbins 2007). 
Fruit, which is unevenly distributed in time and space, is a common food item in the diets of all gorillas, except Karisoke mountain gorillas (Gorilla beringei beringei) in the Virunga Volcanoes of Uganda, Rwanda, and Democratic Republic of Congo (Doran et al. 2002; Ganas et al. 2004; Masi et al. in review; Nkurunungi, 2003; Rogers et al. 2004; Yamagiwa et al. 2003). They live at an ecological extreme of gorilla habitat (high altitude of $>2500 \mathrm{~m}$ ); their diet consists almost entirely of highly abundant, evenly distributed herbaceous vegetation; and they incorporate only a negligible quantity of fruit into their diet (Watts 1984). In general, the degree of gorilla frugivory increases as altitude decreases, with western gorillas (Gorilla gorilla gorilla) incorporating the largest number of fruit species into their diets (Doran and McNeilage 2001; Ganas et al. 2004; Goldsmith 2003; Robbins et al. 2006; Yamagiwa et al. 2003). Further, western gorilla habitat has the lowest density of terrestrial herbaceous vegetation (Doran et al. 2002). The second population of endangered mountain gorillas in Bwindi Impenetrable National Park, Uganda, only ca. $25 \mathrm{~km}$ from the Virunga Volcanoes, is intermediate in food availability and dietary habits because they incorporate fruit into their diets when it is available, yet they also feed heavily on evenly distributed and highly abundant herbaceous vegetation(Ganas et al. 2004; Robbins and McNeilage 2003; Robbins et al. 2006; Nkurunungi 2003).

Owing to the different food availability and distributions for the gorilla populations, I expect to see corresponding differences in feeding competition and social relationships (Doran and McNeilage 1998, 2001). However, our knowledge of the differences is limited because most studies have focused on Karisoke mountain gorillas. As predicted for a dispersal egalitarian species (Sterck et al. 1997; Watts 1994, 1996, 2001, 2003), female dominance relationships among the Karisoke mountain gorillas are generally weak (Harcourt 1979; Robbins et al. 2005; Watts 1985, 1994). Researchers have occasionally detected linear dominance hierarchies from patterns of displacements (Harcourt 1979; Robbins et al. 2005; Watts 1985, 1994), but not when considering all agonistic interactions (Watts 1994). In addition, a high proportion of agonism is directed upward against a hierarchy, the most common response to aggression is to ignore it or to respond with aggression, and females do not exhibit formal dominance/submissive behaviors to each other (Watts 1994, 1996). Further, because females gain no obvious fitness benefit by remaining with kin, they may transfer multiple times (Sicotte 2001; Watts 1990, 1996). The main reasons cited for such dispersal have been inbreeding avoidance and mate choice, not intragroup feeding competition. Though increases in group size have led to higher rates of displacements during foraging (Watts 1985), the mean day journey length (DJL) was relatively constant over a wide range of group sizes, but Watts (1998) predicted it would increase rapidly if groups became even larger.

The only study of social interactions within groups of western gorillas indicated little support for the hypothesis that their higher frugivory led to greater levels of intragroup competition or more strongly differentiated female social relationships than occurred in Karisoke mountain gorillas (Stokes 2004). However, the observations were only in a bai (a large swampy clearing) where the gorillas feed solely on highly abundant, evenly distributed herbaceous vegetation. Researchers have reported no dominance hierarchy for the Bwindi mountain gorillas, but Ganas and Robbins (2005) found that they traveled further on days when they ate fruit than 
on days when they did not. In addition, they found a positive relationship between group size and both daily travel distance and home range size, suggesting that food distribution and availability, in particular that of fruit, may lead to increased levels of intragroup scramble competition at Bwindi. However, it is also possible that energy intake rates are higher when fruit is abundant and so the net gain is actually higher also. Clearly, more detailed studies of intragroup social interactions are needed to understand better the relationship between ecological conditions and the variability of social systems in gorillas.

I tested predictions of feeding competition and agonistic interactions among female mountain gorillas in Bwindi. I also include adult males in much of the analysis because they are also competitors for resources and because they provide a point of comparison with female behavior (Schülke 2003; Watts 1994). First, I used direct observations to approximate the foraging time spent feeding on fruit, to refine the results from previous studies that relied on indirect methods (examining feces and feeding remains: Ganas et al. 2004; Robbins et al. 2006). Second, I sought to determine if fruit trees represent patches containing limited resources and how the gorillas respond competitively to them. As an indication of patch depletion, which is a component of intragroup scramble competition, I predicted that both the number of gorillas using a patch and the total patch occupancy time should correlate positively with the size of the patch (Snaith and Chapman 2005). As an indication of intragroup contest competition, I predicted higher levels of feeding competition while the gorillas foraged on clumped resources (fruit trees) than while they fed on evenly distributed herbaceous vegetation. Further, I tested whether the species of tree, size of the tree, number of gorillas in the tree, or time spent in the tree influenced aggression. Third, to characterize female social relationships, I looked for linear dominance hierarchies based on displacements and on all aggressive interactions. In addition, I examined relationships among the context, intensity, response, and the rank of participants (dominant to subordinate or vice versa) in aggressive interactions.

\section{Methods}

\section{Study Site and Study Group}

I conducted the study in Bwindi Impenetrable National Park $\left(331 \mathrm{~km}^{2}\right)$ in the southwest corner of Uganda $\left(0^{\circ} 53^{\prime} 1^{\circ} 08^{\prime} \mathrm{N} ; 29^{\circ} 35^{\prime}-29^{\circ} 50^{\prime} \mathrm{E}\right)$, with an altitude of 2100-2600 $\mathrm{m}$ for the home range of the study group (Ganas et al. 2004; Nkurunungi 2003; Nkurunungi et al. 2004; Robbins and McNeilage 2003).

I observed the fully habituated Kyagurilo group for $1344 \mathrm{~h}$ on $324 \mathrm{~d}$ across 29 mo between October 1998 and March 2003 (October 1998-September 1999; January 2000, June-September 2000, January-March, June-August 2001, January-March, June, July, December 2002, and February-March 2003).

I used age/sex categories per Watts and Pusey (1993). At the onset of the study, the group comprised 12 gorillas: 1 older silverback/adult male, 2 young silverbacks, 5 adult females, 3 juveniles, and 1 infant. During the study, the following demographic changes occurred: the younger silverbacks emigrated separately in 
November 1999 and November 2000, but 1 rejoined the group in March 2001, and a subadult female emigrated into the group in 2000. Further, 3 births occurred in November 1999, February 2000, and September 2002 and all immature gorillas (all males except 1) advanced to older age classes. At the end of the study, the group comprised 15 gorillas. According to genetic analysis, the adult females of the group are not close kin (Nsubuga 2005).

\section{Data Collection}

I observed the gorillas for an average of $4 \mathrm{~h} / \mathrm{d}$ (range 2-9 h). I collected data via instantaneous scan sampling, focal individual sampling, and observations ad libitum (Altmann 1974). I conducted instantaneous scan samples at 5-min intervals, to measure the amount of time that each individual was in view, and the amount of time spent feeding on fruit, feeding on other food resources, resting (includes social activities), or traveling. In addition, I recorded the activity of the majority of individuals within view as the group activity.

I recorded all agonistic and affiliative interactions during focal individual samples on all 9 adult individuals and ad libitum. Owing to the extremely dense understory vegetation of Bwindi that often limited visibility and maneuverability, and because of efforts to maintain $\geq 7 \mathrm{~m}$ between the gorillas and the observer to reduce the risk of disease transmission, it was often difficult to follow focal individuals for extended periods of time. Therefore, focal observation periods were for $\geq 15 \mathrm{~min}$ and $\leq 60 \mathrm{~min}$. In choosing focal individuals, I gave priority to the individuals with the least amount of focal time, with the aim to collect equal focal observation on all adult individuals. Amount of focal time per individual was 57-83 h (mean=76.4, SD=9.36; lower values were for 2 individuals not in the group for all of the study period) for a total of $625 \mathrm{~h}$ of focal observation.

Agonistic interactions included displacements (approach-retreat interactions), other submissive behavior, and aggression. Displacement occurs when "one individual made a non-aggressive approach to a second, stationary individual, who watched the approacher and, when the approacher was within $2 \mathrm{~m}$, moved more than 2 m farther away" (Watts 1994, p. 348). Other submissive behavior included cowering, avoiding, fleeing, stopping an ongoing behavior such as an approach, and the grumbling vocalization (Watts 1994). I refer to this category as submissive behavior, even though I consider retreats separately, as the response to displacements. I classified aggressive interactions into 3 categories based on increasing intensity of behavior, per Robbins (1996): mild aggression included cough-grunting and screaming (agonistic signals in Watts 1994); moderate aggression comprised any part of the chest-beating or strut-walking sequence typically given by silverbacks (Schaller 1963) and lunges toward the recipient; and high aggression included any behavior involving physical contact including hits, bites, kicks, and attacks. I divided responses to aggression into the following categories per Watts (1994): submissive, ignore, or aggressive, with the latter 2 making the interaction undecided. Owing to the dense vegetation, it was not always possible to identify the recipient of an aggressive act; therefore overall rates of aggression include unknown recipients, but I conducted an analysis in which the recipient is a key variable with a smaller subset of the data. I noted the context of aggression as feeding (fruit or other food 
item), resting, or other. Affiliative behavior included grooming and playing, but I do not discuss it here.

A food patch is defined as an individual tree (Gillespie and Chapman 2001; Pruetz and Isbell 2000; Snaith and Chapman 2005; cf. Saito 1996). On an opportunistic basis, I used the focal patch method to collect data on foraging in fruit trees. Data recorded included the identity of all gorillas, excluding infants $<3 \mathrm{yr}$, in the tree; the time that I first observed each gorilla in the tree or climbing it; and the time that all individuals stopped eating fruit or descended from the tree. I calculated patch occupancy time as the sum of time all gorillas spent in a tree. I also noted if any gorilla foraged for fruit on the ground underneath fruit trees, to test the assumption that if some gorillas were there, either feeding or resting, they may have been unable to forage in the tree owing to the lack of available feeding spots or competition within the tree. To estimate the patch size per tree I recorded its species, height, and crown diameter.

\section{Data Analysis}

To calculate the proportion of time that the group spent eating fruit per day, I divided the number of fruit eating scans by the number of total feeding scans per day. Then I calculated monthly averages. For each fruit species, I calculated the average of crown diameter, number of gorillas in the tree, number of adults in tree, and the total time all gorillas were in the tree.

I calculated hourly rates of aggression by tallying the number of aggressive acts per hour of focal time per individual and compared them via rate-based $\chi^{2}$ tests (Altmann 1977). The gorillas occasionally fed on wood (dead trees), a very clumped resource that led to frequent aggressive interactions (data not shown). I excluded these interactions comparing feeding in specific contexts from analysis, but included them in overall calculations of feeding aggression and agonistic interactions.

To investigate further feeding competition in fruit trees, I first correlated the number of gorillas and the time spent in fruit trees (total patch occupancy time) with the size of trees. Next, I investigated if one can use the following variables to predict the rate of aggression while in fruiting trees: size of tree, number of gorillas feeding in it, elapsed time in tree (time from first gorilla to climb until last gorilla descends), and total gorilla minutes in the tree. Patch occupancy time (total gorilla minutes) in the tree can serve as a rough approximation for the total resources available in the tree (White and Wrangham 1988). I used $\chi^{2}$ tests to test if aggression rates differed within the following categorical variables: whether the full feeding session occurred in each tree, whether there were other gorillas on the ground below the tree, and for differences among tree species.

I calculated dominance hierarchies via $\operatorname{MatMan}^{\mathrm{TM}}$ to calculate the linearity indices of Kendall $(K)$ and an adjusted Landau index $\left(h^{\prime}\right)$ that corrects for the number of relationships that are tied or unknown (deVries 1995). I also investigated the possibility of ranking females into a linear hierarchy via aggressive behavior. Owing to the limitations of using statistical analysis alone to examine dominance relationships (Isbell and Young 2002; Koenig 2002; Koenig and Borries 2006), I examined not only whether the linearity of a hierarchy was statistically significant, but also the number of unknown relationships, 2-way relationships, and the 
percentage of actions upward against the hierarchy. I used $\chi^{2}$ tests to examine whether components of aggressive interactions - intensity, context, response, rank of aggressor and receiver- influenced one another.

\section{Results}

\section{Utilization of Fruit Trees}

The group ate fruit on average $11.2 \%$ of the total feeding time per mo (Fig. 1: $n=29$ mo, range $0-65.5 \%$, median $=6.15, \mathrm{SE}=3.25$ ). Fruit eating occurred on 95 of 324 observation days (29.3\%). Gorillas fed in 403 trees of 15 species, including $\geq 5$ trees in each of 6 major fruit species. I observed from the time of first gorilla climbing to last gorilla descending (total observation per tree) on 227 trees.

For the 6 major fruit species, there is a significant correlation between the average crown diameter and both average number of gorillas feeding in the tree $\left(n=6, r^{2}=\right.$ $0.847, p=0.033$; Fig. 2a) and average number of adults $\left(n=6, r^{2}=0.937, p=0.006\right.$; Fig. 2a), indicating that fruit patch size limits the size of feeding aggregates. In addition, the average crown diameter correlates positively with the average patch occupancy time $\left(n=6, r^{2}=0.911, p=0.012\right.$; Fig. $\left.2 b\right)$, suggesting that the gorillas deplete the fruit trees and experience scramble competition. In addition to the correlations among the major fruit species, significant correlations also existed among the trees for 4 of the 6 species (Table I).

\section{Aggression in Fruit Trees}

Aggression occurred in $c a .40 \%$ of fruit trees containing $>1$ gorilla. I did not observe the total patch occupancy for many trees: the gorillas were already in the tree when I first observed them. Therefore, I tested whether there was a difference in the rate of aggression between 2 types of fruit tree observations: 1) the ones that included the entire session vs. 2) the ones in which the beginning or end of the feeding session was missed. One might expect higher aggression at the beginning or end of feeding

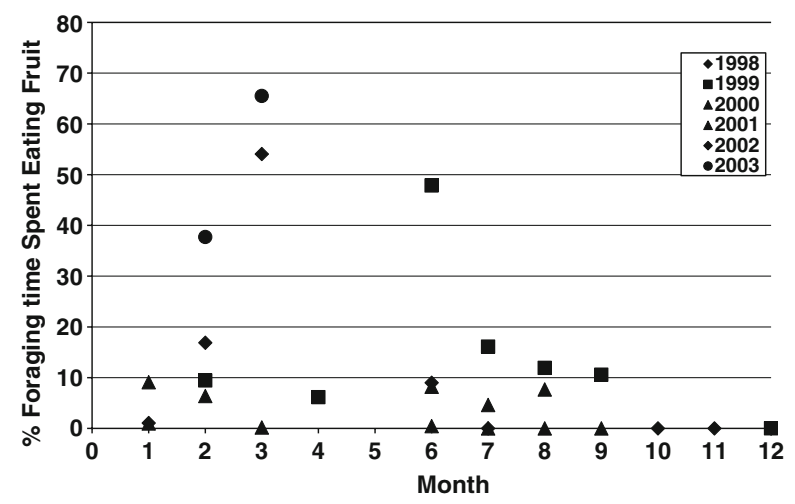

Fig. 1 Percentage of time group activity was spent foraging on fruit per month of observation. 

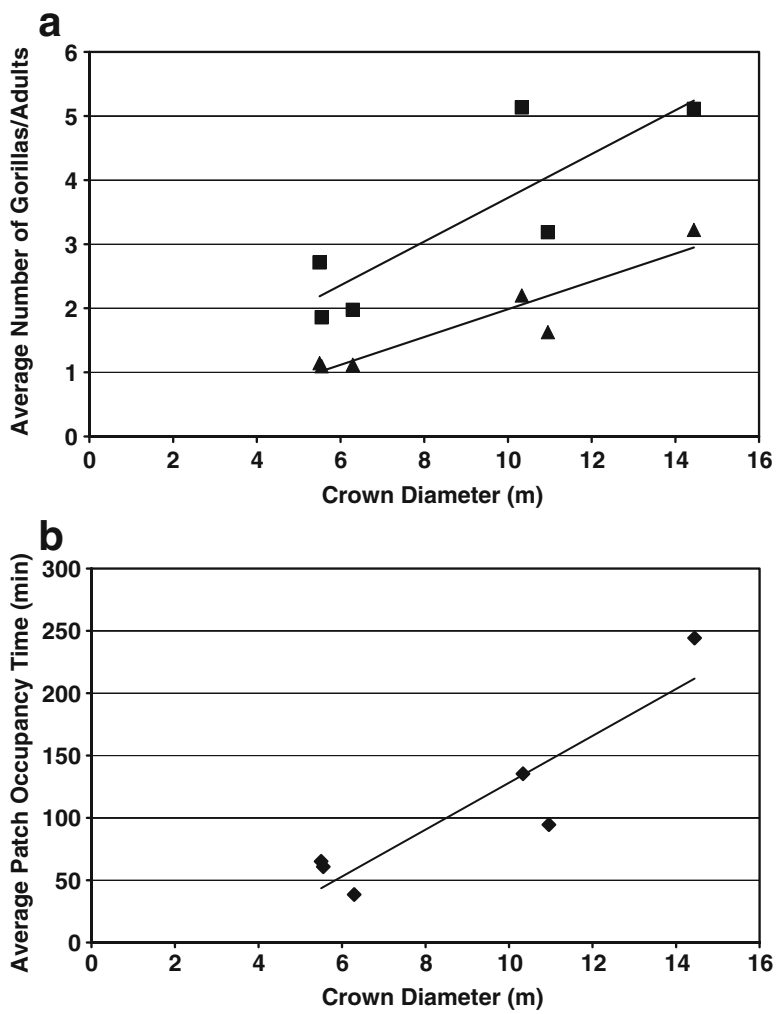

Fig. 2 (A) The average size of the 6 major fruit tree species (crown diameter) versus the average number of gorillas (squares) and adults (triangles) foraging in the tree. (B) The crown diameter versus the average patch occupancy time for the 6 major tree species.

sessions if gorillas initially vie for positions or at the end of sessions if food becomes limited. However, I observed no difference (all gorillas: $\chi^{2}=0.783, \mathrm{df}=1, p=0.376$; adults only: $\chi^{2}=0.119, \mathrm{df}=1, p=0.730$ ), which suggests that the aggression rate is not higher at the beginning or ending of feeding sessions. Therefore all further analysis includes all fruit tree observations.

If some gorillas were on the ground under a fruit tree, either feeding or resting, they might be unable to forage in the tree due to the lack of available feeding spots. Higher aggression might occur when food becomes limited, so I compared the rates of aggression when gorillas were under the trees versus when they were not. Indeed, when gorillas were on the ground below the tree, the aggression rate among all gorillas in the tree was 0.693 acts/gorilla per h, which is significantly higher than the rate of 0.412 when no gorilla was on the ground $\left(\chi^{2}=8.99, \mathrm{df}=1, p=0.003\right)$. The comparison was nearly significant for aggression among adults: 0.617 acts/adult per $\mathrm{h}$ with gorillas on the ground, vs. 0.494 with no gorilla on the ground $\left(\chi^{2}=3.52\right.$, $\mathrm{df}=1, p=0.061$ ).

Average aggression rates with all gorillas included in the analysis differed significantly among tree species $\left(\chi^{2}=28.6, \mathrm{df}=7, p<0.001\right)$. Two species accounted for $83 \%$ of the $\chi^{2}$ value: the rate was lower than expected for Chrysophyllum, and 
Table I Average values for crown diameter (m), number of gorillas occupying trees (gorillas), number of adults occupying trees (adults), and patch occupancy time (time in min) of 6 major tree species

\begin{tabular}{|c|c|c|c|c|c|c|c|c|}
\hline \multirow[t]{2}{*}{ Species } & \multirow[t]{2}{*}{$N$} & \multicolumn{4}{|c|}{$\begin{array}{l}\text { Average values for each } \\
\text { species }\end{array}$} & \multicolumn{3}{|c|}{ Intraspecific relationships } \\
\hline & & Size & Gorillas & Adults & Time & Size vs. gorillas & Size vs. adults & Size vs. time \\
\hline Olea capensis & 9 & 14.4 & 5.1 & 3.2 & 244.2 & $0.614(0.078)$ & $0.802(0.009)$ & $0.697(0.037)$ \\
\hline Chrysophyllum sp. & 43 & 11.0 & 3.2 & 1.6 & 94.6 & $0.478(0.001)$ & $0.345(0.023)$ & $0.319(0.037)$ \\
\hline Myrianthus holstii & 15 & 10.3 & 5.1 & 2.2 & 135.3 & $0.296(0.285)$ & $0.228(0.414)$ & $0.259(0.350)$ \\
\hline Syzigium sp. & 42 & 6.3 & 2.0 & 1.1 & 38.5 & $0.726(0.001)$ & $0.617(0.001)$ & $0.744(0.001)$ \\
\hline Drypetes gerrardii & 86 & 5.6 & 1.9 & 1.1 & 60.8 & $0.403(0.001)$ & $0.451(0.001)$ & $0.354(0.001)$ \\
\hline Maesa lanceolata & 22 & 5.5 & 2.7 & 1.1 & 65.1 & $0.388(0.082)$ & $0.215(0.348)$ & $0.242(0.278)$ \\
\hline
\end{tabular}

See text for statistical relationships among average values of the species. For intraspecific relationships among individual trees, this table shows the $R^{2}$ value, followed by the $p$-value in parentheses. $n=$ Number of trees observed for each species.

higher than expected for Syzigium. I performed a stepwise multiple regression to look for the sources of variance among the tree species, which revealed that the average aggression rate increased significantly for species with a higher average number of gorillas in the tree $\left(F_{11,1}=12.9, R^{2}=0.54, p=0.004\right)$, but it does not significantly correlate with the average height or diameter of the tree, the average elapsed feeding time, total patch occupancy time, or the proportion of sessions with gorillas on the ground. The result may indicate that no variable related to the patch size influenced the rate of aggression independently, but because patch size correlates positively with the number of individuals in a tree, the rate of aggression increases as more individuals participate. I obtained similar results when I used only adult gorillas.

\section{Broader Context of Aggression and Displacements}

During feeding, $66 \%$ of the aggression was between 2 females, whereas $70 \%$ of aggression during nonfeeding was between a male and a female. The significant difference $\left(\chi^{2}=94.33, \mathrm{df}=1, p<0.001\right)$ is probably due to the high proportion of male to female displays used as a male mating strategy (Robbins 2003; Watts 1992). Silverbacks had 0.32 aggressive acts/gorilla per focal $\mathrm{h}$ during feeding, which is significantly lower than their rate of 1.1 when not feeding $\left(\chi^{2}=33.4, \mathrm{df}=1, p<\right.$ $0.001)$, which provides further evidence that much of their aggression is unrelated to feeding competition (Fig. 3). In contrast, adult females had a significantly higher rate of aggression during feeding (0.21 aggressive acts/gorilla per focal h, vs. 0.094 when not feeding, $\left.\chi^{2}=9.5, \mathrm{df}=1, p=0.002\right)$. The aggression rate for adult females was 0.47 when feeding on fruit, which is significantly higher than their rate of 0.14 when feeding on herbaceous foods $\left(\chi^{2}=18.4, \mathrm{df}=1, p<0.001\right)$. However, the female aggression rate for herbaceous foods was not higher than for nonfeeding $\left(\chi^{2}=1.6\right.$, $\mathrm{df}=1, p=0.21$ ). The results suggest that feeding on clumped food resources, in this case fruit, leads to higher levels of intragroup contest competition than more evenly distributed herbaceous vegetation does.

Displacements were more likely to occur while feeding than during nonfeeding activities (all adults, $\chi^{2}=56.49, \mathrm{df}=1, p<0.001$; adult females only, $\chi^{2}=13.85, \mathrm{df}=1$, 


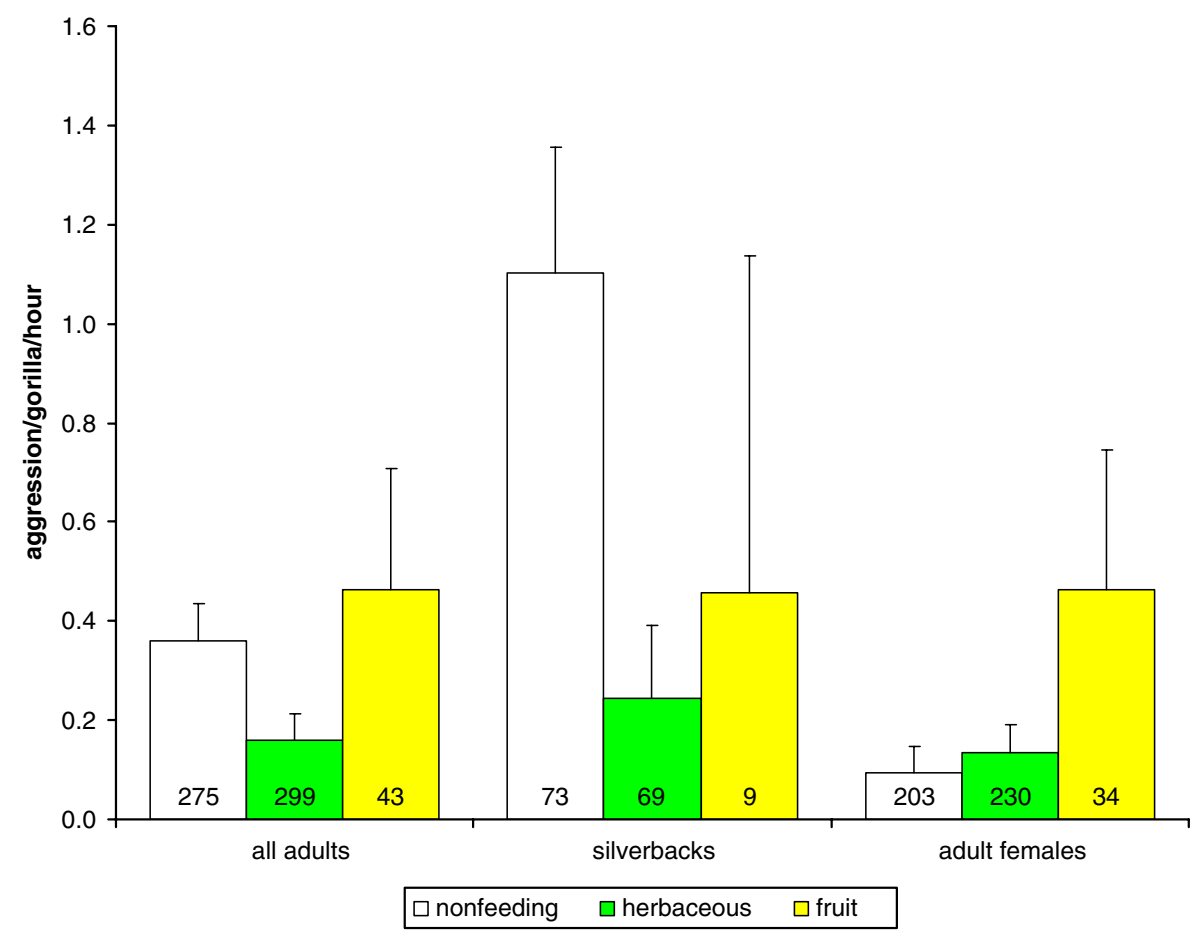

Fig. 3 Rate of aggression per focal hour of observations for nonfeeding, feeding on primarily herbaceous foods, and feeding on fruit. Rates for all adults, for adult males (silverbacks), and for adult females. Error bars show the upper $95 \%$ confidence intervals, and the numbers at the base of each bar indicate the focal hours of observation.

$p<0.001)$. There is no difference in the rate of displacement while feeding on fruit versus feeding on other food resources (all adults, $\chi^{2}=0.568, \mathrm{df}=1, p=0.451$; adult females only $\left(\chi^{2}=0.003, \mathrm{df}=1, p=0.954\right)$. The overall rate of displacements given and received per focal $\mathrm{h}$ was low. The dominant silverback gave displacements at a rate that was 3-5 times higher ( 0.49 per focal $h$; he was never displaced) than that given and received by any individual adult female (0.09-0.16 displacements per focal $h)$.

\section{Dominance Hierarchies Based on Aggression and Displacements}

Based on displacements, a significantly linear dominance hierarchy occurred among the adult males and females ( $h=0.82, p=0.01$; Tables II and III, test a). When considering only the adult females, the resulting hierarchy is no longer statistically significant $(p=0.08)$, but $h=0.85$, indicating a degree of linearity similar to that when the adult males were included (Table III, test $3 \mathrm{~b}$ ). No displacement is directed from lower- to higher-ranking females, but with only 6 individuals in the hierarchy, statistical significance is not possible because 2 of the 15 dyads (13.3\%) had no displacement in either direction. 
Table II Dominance relationships among adult gorillas based on approach-retreat interactions (displacements) from focal observations and observations ad libitum

\begin{tabular}{llllllllll}
\hline & ZS & RC & BY & ST & MT & KK & MG & TN & Total \\
\hline ZS & X & 2 & 18 & 31 & 14 & 12 & 17 & 9 & 103 \\
RC & 0 & X & 0 & 1 & 1 & 0 & 0 & 3 & 5 \\
BY & 0 & 0 & x & 2 & 4 & 2 & 3 & 3 & 14 \\
ST & 0 & 0 & 0 & x & 2 & 2 & 5 & 1 & 10 \\
MT & 0 & 0 & 0 & 0 & x & 1 & 0 & 0 & 1 \\
KK & 0 & 0 & 0 & 0 & 0 & x & 1 & 1 & 2 \\
MG & 0 & 0 & 0 & 0 & 0 & 0 & X & 2 & 2 \\
TN & 0 & 0 & 0 & 0 & 0 & 0 & 0 & x & 0 \\
Total & 0 & 2 & 18 & 34 & 21 & 17 & 26 & 19 & 137 \\
\hline
\end{tabular}

ZS and RC are silverbacks, TN was subadult from 2000 to 2002, and all others are adult females. Rows are the actors and columns are the recipients.

More data are available for hierarchies via aggressive interactions, and there is a significant linear hierarchy among the adult females $(h=0.914, p=0.021)$, even though $24.6 \%$ of that aggression was directed from subordinate females toward higher-ranking individuals (Table III, test 3c). The rank order based on aggression did not exactly match that established for displacements, because female ST dropped from second- to fifth-ranking. The hierarchy was similar when I limited the analysis to low-intensity aggression, which accounts for more than two-thirds of the interactions (Table III, test 3d). When I limited the analysis to moderate and highintensity aggression, the number of 2-way relationships and the percentage of interactions upward against the hierarchy both declined, and ST returned to second rank (Table III, test 3e).

Table III Summary of dominance hierarchies using different sets of agonistic interactions

\begin{tabular}{|c|c|c|c|c|c|c|c|c|}
\hline Test & Data set & $\begin{array}{l}\text { Rank } \\
\text { order }\end{array}$ & $n$ & $h$ & $p$ & $\begin{array}{l}\text { No. of } \\
\text { unknown } \\
\text { relationships }\end{array}$ & $\begin{array}{l}\text { No. of } \\
\text { 2-way } \\
\text { relationships }\end{array}$ & $\begin{array}{l}\% \text { actions } \\
\text { upward } \\
\text { against } \\
\text { hierarchy }\end{array}$ \\
\hline $3 a$ & $\begin{array}{l}\text { Displacements } \\
\text { and avoidances, } \\
\text { all adults }\end{array}$ & $\begin{array}{l}\text { ZS, BY, RC, } \\
\text { ST, MT, KK, } \\
\text { MG, TN }\end{array}$ & 137 & 0.761 & 0.01 & 5 & 0 & 0 \\
\hline $3 b$ & $\begin{array}{l}\text { Displacements } \\
\text { and avoidances, } \\
\text { females only }\end{array}$ & $\begin{array}{l}\mathrm{BY}, \mathrm{ST}, \mathrm{MT}, \\
\mathrm{KK}, \mathrm{MG}, \mathrm{TN}\end{array}$ & 29 & 0.857 & 0.08 & 2 & 0 & 0 \\
\hline $3 c$ & $\begin{array}{c}\text { All aggression, } \\
\text { females only }\end{array}$ & $\begin{array}{r}\text { BY, MT, KK, } \\
\text { MG, ST, TN }\end{array}$ & 325 & 0.914 & 0.021 & 0 & 14 & 24.6 \\
\hline $3 d$ & $\begin{array}{l}\text { Low aggression } \\
\text { only }\end{array}$ & $\begin{array}{l}\text { BY, MT, KK, } \\
\text { MG, ST, TN }\end{array}$ & 223 & 0.914 & 0.021 & 0 & 15 & 25.6 \\
\hline $3 e$ & $\begin{array}{l}\text { Moderate and } \\
\text { high aggression } \\
\text { only }\end{array}$ & $\begin{array}{l}\text { BY, ST, KK, } \\
\text { MT, MG, TN }\end{array}$ & 102 & 0.942 & 0.019 & 1 & 8 & 19.6 \\
\hline
\end{tabular}

ZS and RC are silverbacks, TN was subadult from 2000 to 2002, and all others are adult females. Hierarchies with aggression include adult females only. $n=$ number of interactions per category. Number of unknown and 2-way relationships is out of a maximum of 15 female-female dyads. 
The rate of overall feeding aggression by females correlates positively to their dominance rank based on displacements $\left(n=6, r^{2}=0.720, p=0.033\right)$, but there is no significant correlation within each of the specific contexts of feeding aggression (fruit, nonfruit foods). There is no relationship between the rank of the aggressor and the context of the aggression $\left(\chi^{2}=1.33, n=325, \mathrm{df}=2, p=0.514\right)$.

\section{Intensity of Aggression}

The majority of aggression (77.6\%) among adult females was mild and only $12.7 \%$ was moderate. When including adult males, roughly the same proportion was mild and moderate, $43.3 \%$ and $44 \%$, respectively. Relatively little aggression involved physical contact (high); $12.7 \%$ including all adults, 9.7\% including only adult females. To investigate the influences on the intensity of aggression, I combined the moderate and high aggression categories. Contexts I considered are feeding on nonfruit (excluding wood), feeding on fruit, and other (combined rest, travel, and other).

There is a significant difference in the intensity of aggression in different contexts (Table IVA; $\chi^{2}=71.19, n=325, \mathrm{df}=3, p<0.001$ ). Analysis post hoc showed that aggression was more likely to be mild while feeding than in other contexts, and also more likely to be mild when feeding on fruit than other foods: $95 \%$ of aggression was mild when the females were feeding on fruit, $81 \%$ was mild when feeding on non-fruit, and 55\% was mild in other contexts (fruit vs. nonfruit feed: $\chi^{2}=4.88, n=$ $141, \mathrm{df}=1, p=0.027$; fruit vs. other: $\chi^{2}=24.44, n=228, \mathrm{df}=1, p<0.001$; feed nonfruit vs. other: $=18.74, n=281, \mathrm{df}=1, p<0.001$ ). So although feeding (especially on fruit) increases the rate of aggression, it does not increase the intensity of aggression.

Table IV Aggressive interactions and responses among adult females according to the context, intensity, and relative rank of participants

A. Intensity of aggression

\begin{tabular}{|c|c|c|c|}
\hline & Mild & Medium/high & \\
\hline \multicolumn{4}{|l|}{ Context } \\
\hline Feed: nonfruit & 79 & 18 & \\
\hline Feed: fruit & 42 & 2 & \\
\hline Other & 102 & 82 & \\
\hline \multicolumn{4}{|l|}{ Rank } \\
\hline Higher to lower & 140 & 83 & \\
\hline Lower to higher & 82 & 20 & \\
\hline \multicolumn{4}{|c|}{ B. Responses to aggression } \\
\hline & Ignore & Submit & Retaliate \\
\hline \multicolumn{4}{|l|}{ Intensity } \\
\hline Low & 181 & 17 & 25 \\
\hline Medium/high & 90 & 3 & 9 \\
\hline \multicolumn{4}{|l|}{ Context } \\
\hline Feed: nonfruit & 76 & 12 & 9 \\
\hline Feed: fruit & 34 & 2 & 8 \\
\hline Other & 161 & 6 & 17 \\
\hline \multicolumn{4}{|l|}{ Rank } \\
\hline Higher to lower & 187 & 17 & 18 \\
\hline Lower to higher & 84 & 3 & 16 \\
\hline
\end{tabular}


In a comparison of intensity and rank, via the hierarchy obtained from displacements for rankings (Table II), when the aggressor had higher rank than the subordinate, $37 \%$ of aggression was moderate/high, which is significantly higher than the $19 \%$ proportion when the aggressor had lower rank (Table IVA; $\chi^{2}=10.03$, $n=325, \mathrm{df}=1, p=0.002$ ).

\section{Responses to Aggression}

The gorillas exhibited a high proportion of undecided aggressive interactions. Of aggression received in female-female interactions, subjects ignored $83.3 \%, 10.5 \%$ involved returned aggression (retaliation), and 6.2\% elicited submissive behavior. In comparison, the responses to aggression received by females from silverbacks was $81.5 \%$ ignored, 2.5\% returned aggression (always mild cough grunting), and 16\% elicited submissive behavior. Submission was more likely to occur in response to aggression initiated by a silverback than that by another female $\left(\chi^{2}=10.38, \mathrm{df}=1, p<0.01\right)$.

The response to aggression did not vary according to the intensity of aggression given (Table IVB; $\chi^{2}=3.29, n=325, \mathrm{df}=2, p=0.193$ ), but the response varied according to the context of aggression $\left(\chi^{2}=12.54, n=325, \mathrm{df}=4, p=0.014\right)$. Analyses post hoc revealed the following significant relationships between the context of aggression and the response: When subjects ignored the aggression, retaliation (returned aggression) was more likely during feeding than during nonfeeding $\left(\chi^{2}=4.38, n=44, \mathrm{df}=1, p=0.036\right)$ and when feeding on fruit versus nonfruit $\left(\chi^{2}=3.77, n=31, \mathrm{df}=1, p=0.052\right)$. Thus, retaliation became more likely when more was at stake. However, when the response was not retaliation, submission was more likely during feeding than during nonfeeding $\left(\chi^{2}=8.86, n=\right.$ 255, $\mathrm{df}=1, p=0.003)$.

The response to aggression varied according to rank of the aggressor (Table IVB; $\chi^{2}=6.34, \mathrm{n}=325, \mathrm{df}=2, p=0.042$ ). Comparisons post hoc revealed that subjects were just as likely to ignore aggression by higher-ranking females as they did aggression from lower-ranking females ( $84 \%$ vs. $\left.82 \% ; \chi^{2}=0.37, n=325, \mathrm{df}=1, p=0.546\right)$. However, when subjects did not ignore the aggression, higher-ranked females were more likely to retaliate $\left(16 \%\right.$ vs. $\left.8 \% ; \chi^{2}=4.14, \mathrm{n}=325, \mathrm{df}=1, p=0.042\right)$, whereas lower-ranked females exhibited a trend toward being more likely to respond with submissive behavior ( $8 \%$ vs. $3 \% ; \chi^{2}=2.74, n=325, \mathrm{df}=1, p=0.098$ ). Similarly, while there is no correlation between rank and the proportion of responses to aggression by each female that were submissive $\left(n=6, r^{2}=0.094, p=0.556\right)$, there is a positive correlation between rank and the proportion of responses to aggression received by each female that was aggressive $\left(n=6, r^{2}=0.631, p=0.036\right)$.

\section{Discussion}

Frugivory and Patch Utilization

I provide some of the first quantification of frugivory and the associated behavioral responses in gorillas via direct observations (Doran-Sheehy 2006; Masi et al. in review). Though overall, the gorillas spent $c a$. $11 \%$ of their foraging time eating 
fruit, there is high variability among months (0-65\%) and between years (Nkurunungi 2003; Robbins et al. 2006). The remainder of their foraging time is devoted primarily to consuming evenly distributed herbaceous vegetation. While fruit is not the major component of the diet for Bwindi gorillas, they consume it frequently enough to warrant investigation of its influence on feeding competition.

As commonly found in many primate species, both the number of individuals feeding in fruit trees and total patch occupancy time correlate positively with the size of the trees (Isabirye-Basuta 1988; Janson 1987; Leighton and Leighton 1982; Snaith and Chapman 2005; Stevenson et al. 1998; Strier 1989; Symington 1988; White and Wrangham 1988). The results provide indirect evidence that the size of the fruit trees limits the number of individuals using them because of patch depletion, and that the fruit trees are not superabundant patches for gorillas.

I also show that typically only a fraction of the entire group foraged together in the same tree. Even without contest competition, a decision to climb a tree may depend on both the amount of food and the number of competitors already in the tree; it may not be worth climbing a tree unless the expected rewards are great enough. For example, there were cases of individuals on the ground feeding on herbaceous vegetation or resting while other group members fed in fruit trees, occasions when members of the group were simultaneously feeding in $>1$ tree, often spread apart by $\geq 100 \mathrm{~m}$, and cases wherein subordinate females arrived at a fruit tree after more dominant females and waited until they departed before climbing to feed. Hence individual fruit trees may represent limiting resources. However, in many cases the availability of other fruit and herbaceous vegetation sources may not have led to differential food intake among group members.

Patch depletion indicates scramble competition (Snaith and Chapman 2005). Further evidence for scramble competition in Bwindi gorillas is that daily travel distance increased as both group size and frugivory increased (Ganas and Robbins 2005). In contrast, Karisoke mountain gorillas, which feed upon abundant, evenly distributed herbaceous vegetation, show little or no evidence of the costs of scramble competition because mean day journey length (DJL) was relatively constant over a wide range of group sizes (Watts 1998) and group size had no effect on female reproductive success (Robbins et al. 2007).

\section{Agonistic Interactions}

Bwindi gorillas exhibited higher rates of aggression while foraging on fruit than on other food resources, suggesting that contest competition increases as they forage on depletable, limited, and apparently monopolizable patches, as occurs in several other primate species. Displacements were more likely to occur during feeding than during other activities, an indication of interference competition, but they were equally likely to occur while subjects fed on fruit vs. other food resources. The rates of aggression increased as the number of individuals foraging in a fruit tree increased and when they foraged in and under the tree (an indication of lack of feeding spaces in the tree), both indicating that contest competition increased as amount of food available per individual in a patch decreased (relative patch size).

The results represent stronger evidence of intragroup contest competition than Stokes (2004) and Watts (1994) reported for other populations of gorillas. Nonetheless, the evidence suggests that any contest competition is still relatively 
mild. The majority of aggression among females was mild, most was ignored or undecided, and very few aggressive acts led to submissive behavior, which is similar to observations at Karisoke (Watts 1994). Mild aggression was more likely to occur when subjects were feeding, and more likely when they fed on fruit than on other foods. Mild aggression may be more likely when individuals feed on fruits because of the risks involved in higher levels of aggression and reduced mobility while they are in trees. Contest competition may be weak because high-quality alternatives are available. Individuals that are excluded from a feeding site may be able to forage easily in another fruit tree or on herbaceous vegetation to reduce intragroup competition (Pazol and Cords 2005). As with several other species, Bwindi mountain gorillas may use spatial mechanisms such as increasing group spread to avoid directly competitive situations (Barton 1993; Pazol and Cords 2005; Symington 1988; van Schaik and van Noordwijk 1988).

\section{Dominance Relationships}

When I ranked females according to displacements, there was no behavior upward against the hierarchy (subordinate individuals displacing more dominant individuals), and the $h$ value is relatively high, but the linearity is not statistically significant owing to missing values for 2 dyads. I could also assign adult females to a linear dominance hierarchy via several combinations of aggressive interactions (Table III), though there were several 2way relationships and actions upward against the hierarchy. When I removed coughgrunting, a mild aggressive signal, the proportion of behaviors upward against the hierarchy declined, suggesting that the vocalizations may be a very weak form of aggression that relates little to the establishment and maintenance of dominance relationships. The results emphasize potential computational challenges in quantitative comparisons of results within/between studies, especially when sample sizes differ (Koenig and Borries 2006). For example, it seemed ironic to find a stronger $p$-value for a matrix with $25 \%$ upward interactions (all aggression) than for a matrix with no upward interactions (displacements). Further support for the strength of dominance relationships comes from analysis of the intensity of and response to aggression according to dominance rank. High-ranking individuals were more likely to give moderate/high levels of aggression than low- ranking ones were, and they were also more likely to retaliate to aggression than subordinates, which were more likely to show submission to aggression.

Accordingly, female Bwindi mountain gorillas may exhibit relatively weak individualistic dominance relationships that are similar to the ones in their counterparts at Karisoke (Robbins et al. 2005; Watts 1994, 2003). The universality of dispersal by female gorillas (Robbins et al. 2004; Sicotte 2001; Stokes et al. 2003; Yamagiwa and Kahekwa 2001;) indicates either that no population studied experiences feeding competition to a degree that would lead to strong female nepotism or that dispersal is largely driven by other factors such as inbreeding avoidance, mate choice, or phylogenetic constraints (Sicotte 2001). Both mountain gorilla populations also seem similar to other species/populations that exhibit both female dispersal and linear dominance hierarchies: chimpanzees (Murray et al. 2006; Wittig and Boesch 2003), fairy leaf monkeys (Koenig et al. 2004), and mantled howlers (Zucker and Clarke 1998). The studies suggest that even when ecological 
conditions do not make the benefits of philopatry greater than those of dispersal, they can still lead to competitive regimes that include stable dominance hierarchies. Further, dominance rank correlates positively with reproductive success in 2 other ape populations with female dispersal and supposedly weak female dominance relationships: Gombe chimpanzees (Pusey et al. 1997) and Karisoke mountain gorillas (Robbins et al. 2007).

\section{Gorillas and the Socioecological Model}

The socioecological model proposes that the distribution, density, and quality of food resources impact competitive interactions during feeding, which in turn influence type of female social relationships (Isbell and Young 2002; Koenig 2002; Sterck et al. 1997; van Schaik 1989; Wrangham 1980). In particular, clumped resources are predicted to promote female philopatry and strong nepositic relationships. However, Sterck et al. (1997, p. 294) also proposed that "although the underlying ecological variation is continuous, the social responses are more or less discrete." Thus, one potential value of studying species with weak dominance relationships is to find the threshold at which ecological variations become great enough to cause a discrete change in social response. Clumped resources (fruit) comprise a greater proportion of the diet for Bwindi gorillas than for Karisoke gorillas, but my results suggest that the ecological differences are not sufficient to cause a discrete change in social response. More detailed studies could enhance our quantification of the ecological variations, and test whether they lead to subtle differences in social responses. The studies should include refined measures of density and abundance of both fruit and herbaceous vegetation (patch size) and should examine how scramble and contest competition both influence differentiated dietary intake, energy expenditure, and/or reproductive success according to dominance rank and group size (Isbell and Young 2002; Janson 1985, 1988; Koenig 2002; Whitten 1983).

Acknowledgments I thank the Uganda Wildlife Authority and the Uganda National Council of Science and Technology for their permission and long-term support of the research. The Institute for Tropical Forest Conservation and Alastair McNeilage provided invaluable logistical support. I thank all the field assistants of ITFC for their dedicated work with the gorillas, especially Tibenda Emmanuel, Twinomujuni Gaad, Mbabazi Richard, Ngamganeza Caleb, Kyamuhangi Narsis, Byaruhanga Gervasio, Twebaze Deo, Mayooba Godfrey, Tumwesigye Philimon, and Murembe Erinerico. The manuscript benefited greatly from discussions and comments from Christophe Boesch, Daniel Stahl, Alastair McNeilage, and especially Andrew Robbins. The Max Planck Society provided funds for the project.

Open Access This article is distributed under the terms of the Creative Commons Attribution Noncommercial License which permits any noncommercial use, distribution, and reproduction in any medium, provided the original author(s) and source are credited.

\section{References}

Altmann, J. (1974). Observational study of behaviour: Sampling methods. Behaviour, 49, 227-265. doi:10.1163/156853974X00534.

Altmann, S. A., \& Altmann, J. (1977). On the analysis of rates of behaviour. Animal Behaviour, 25, 364372 . 
Barton, R. A. (1993). Sociospatial mechanisms of feeding competition in female olive baboons. Papio Anubis. Animal Behaviour, 46, 791-802. doi:10.1006/anbe.1993.1256.

Barton, R. A., Byrne, R. W., \& Whiten, A. (1996). Ecology, feeding competition and social structure in baboons. Behavioral Ecology and Sociobiology, 38, 321-329. doi:10.1007/s002650050248.

Barton, R. A., \& Whiten, A. (1993). Feeding competition among female olive baboons. Papio Anubis. Animal Behaviour, 46, 777-789. doi:10.1006/anbe.1993.1255.

Boinski, S., Sughure, K., Selvaggi, L., Quatrone, R., Henry, M., \& Cropp, S. (2002). An expanded test of the ecological model of primate social evolution: Competitive regimes and female bonding in three species of squirrel monkeys (Saimiri oerstedii, S. boliviensis and S. sciureus). Behaviour, 139, 227261. doi:10.1163/156853902760102663.

de Vries, H. (1995). An improved test of linearity in dominance hierarchies containing unknown or tied relationships. Animal Behaviour, 50, 1375-1389. doi:10.1016/0003-3472(95)80053-0.

Doran, D. M., \& McNeilage, A. (1998). Gorilla ecology and behavior. Evolutionary Anthropology, 6, 120-131. doi:10.1002/(SICI)1520-6505(1998)6:4<120::AID-EVAN2>3.0.CO;2-H.

Doran, D. M., \& McNeilage, A. (2001). Subspecific variation in gorilla behavior: the influence of ecological and social factors. In M. M. Robbins, P. Sicotte, \& K. J. Stewart (Eds.), Mountain Gorillas: Three Decades of Research at Karisoke (pp. 123-149). Cambridge, U.K.: Cambridge University Press.

Doran, D. M., McNeilage, A., Greer, D., Bocian, C., Mehlman, P. T., \& Shah, N. (2002). Western lowland gorilla diet and resource availability: New evidence, cross-site comparisons, and reflections on indirect sampling methods. American Journal of Primatology, 58, 91-116. doi:10.1002/ajp.10053.

Doran-Sheehy, D. M., Shah, N. F., \& Heimbauer, L. A. (2006). Sympatric western gorilla and mangabey diet: Re-examination of ape and monkey foraging strategies. In G. Hohmann, M. M. Robbins, \& C. Boesch (Eds.), Feeding Ecology in Apes and Other Primates: Ecological, Physical, and Behavioral Aspects (pp. 47-68). Cambridge, U.K.: Cambridge University Press.

Ganas, J., \& Robbins, M. M. (2005). Ranging behavior of the mountain gorillas (Gorilla beringei beringei) in Bwindi Impenetrable National Park, Uganda: A test of the ecological constraints model. Behavioral Ecology and Sociobiology, 58, 277-288. doi:10.1007/s00265-005-0920-z.

Ganas, J., Robbins, M. M., Nkurunungi, J. B., Kaplin, B. A., \& McNeilage, A. (2004). Dietary variability of mountain gorillas in Bwindi Impenetrable National Park, Uganda. -. International Journal of Primatology, 25, 1043-1072. doi:10.1023/B:IJOP.0000043351.20129.44.

Gillespie, T. R., \& Chapman, C. A. (2001). Determinants of group size in the red colobus monkey (Procolobus badius): An evaluation of the generality of the ecological-constraints model. Behavioral Ecology and Sociobiology, 50, 329-338.

Goldsmith, M. L. (2003). Comparative behavioral ecology of a lowland and highland gorilla population: Where do Bwindi gorillas fit. In A. B. Taylor, \& M. L. Goldsmith (Eds.), Gorilla Biology: A Multidisciplinary Perspective (pp. 358-384). Cambridge, U.K.: Cambridge University Press.

Harcourt, A. H. (1979). Social relationships among adult female mountain gorillas. Animal Behaviour, 27, 251-264. doi:10.1016/0003-3472(79)90145-3.

Isabirye-Basuta, G. (1988). Food competition among individuals in a free-ranging chimpanzee community in Kibale Forest, Uganda. Behaviour, 105, 135-147. doi:10.1163/156853988X00485.

Isbell, L. A., \& Pruetz, J. D. (1998). Differences between vervets (Cercopithecus aethiops) and patas monkeys (Erythrocebus patas) in agonistic interactions between adult females. International Journal of Primatology, 19, 837-855. doi:10.1023/A:1020393329574.

Isbell, L. A., Pruetz, J. D., \& Young, T. P. (1998). Movements of vervets (Cercopithecus aethiops) and patas monkeys (Erythrocebus patas) as estimators of food resource size, density, and distribution. Behavioral Ecology and Sociobiology, 42, 123-133. doi:10.1007/s002650050420.

Isbell, L. A., \& Young, T. P. (1993). Social and eocological influences on activity budgets of vervet monkeys, and their implications for group living. Behavioral Ecology and Sociobiology, 32, 377-385.

Isbell, L. A., \& Young, T. P. (2002). Ecological models of female social relationships in primates: Similarities, disparities, and some directions for future clarity. Behaviour, 139, 177-202. doi:10.1163/ 156853902760102645.

Janson, C. H. (1985). Aggressive competition and individual food consumption in wild brown capuchin monkeys (Cebus apella). Behavioral Ecology and Sociobiology, 18, 125-138. doi:10.1007/ BF00299041.

Janson, C. H. (1987). Food competition in brown capuchin monkeys (Cebus aplella): Quantitative effects of group size and tree productivity. Behaviour, 12, 53-76.

Janson, C. H. (1988). Food competition in brown capuchin monkeys (Cebus apella): Quantitative effects of group size and tree productivity. Behaviour, 105, 53-76. doi:10.1163/156853988X00449. 
Janson, C. H., \& van Schaik, C. P. (1988). Recognizing the many faces of primate food competition: Methods. Behaviour, 105, 165-186. doi:10.1163/156853988X00502.

Koenig, A. (2000). Competitive regimes in forest-dwelling Hanuman langur females (Semnopithecus entellus). Behavioral Ecology and Sociobiology, 48, 93-109. doi:10.1007/s002650000198.

Koenig, A. (2002). Competition for resources and its behavioral consequences among female primates. International Journal of Primatology, 23, 759-783. doi:10.1023/A:1015524931226.

Koenig, A., Beise, J., Chalise, M. K., \& Ganzhorn, J. U. (1998). When females should contest for food-testing hypotheses abut resource density, distribution, size, and quality with Hanuman langurs (Presbytis entellus). Behavioral Ecology and Sociobiology, 42, 225-237. doi:10.1007/s002650050434.

Koenig, A., \& Borries, C. (2006). The predictive power of socioecological models: A reconsideration of resource characteristics, agonism, and dominance hierarchies. In G. Hohmann, M. M. Robbins, \& C. Boesch (Eds.), Feeding Ecology in Apes and Other Primates: Ecological, Physical, and Behavioral Aspects (pp. 261-282). Cambridge, U.K.: Cambridge University Press.

Koenig, A., Larney, E., Lu, A., \& Borries, C. (2004). Agonistic behavior and dominance relationships in female Phayre's leaf monkeys-preliminary results. American Journal of Primatology, 64, 351-357. doi:10.1002/ajp.20084.

Leighton, M., \& Leighton, D. (1982). The relationship of size of feeding aggregate to size of food patch: Howler monkeys (Alouatta palliata) feeding in Trichilia cipo fruit trees on Barro Colorado Island. Biotropica, 14, 81-90. doi:10.2307/2387735.

Masi, S., Cipolletta, C., \& Robbins, M. M. In review. Western lowland gorillas (Gorilla gorilla gorilla) change activity patterns in response to frugivory

Mitchell, C. L., Boinski, S., \& van Schaik, C. P. (1991). Competitive regimes and female bonding in two species of squirrel monkeys (Saimiri oerstedi and S. sciureus). Behavioral Ecology and Sociobiology, 28, 55-60. doi:10.1007/BF00172139.

Murray, C. M., Eberly, L. E., \& Pusey, A. E. (2006). Foraging strategies as a function of season and rank among wild female chimpanzees (Pan troglodytes). Behavioral Ecology, 17, 1020-1028. doi:10.1093/ beheco/arl042.

Nkurunungi, J. B. (2003). Feeding and Ranging Behavior of Mountain Gorillas (Gorilla g. beringei) in Bwindi Impenetrable National Park, Uganda. Ph.D. dissertation, Makerere University, Uganda.

Nkurunungi, J. B., Ganas, J., Robbins, M. M., \& Stanford, C. B. (2004). A comparison of two mountain gorilla habitats in Bwindi Impenetrable National Park, Uganda. African Journal of Ecology, 42, 289297. doi:10.1111/j.1365-2028.2004.00523.x.

Nsubuga, A. M. (2005). Genetic Analysis of the Social Structure in Wild Mountain Gorillas (Gorilla beringei beringei) of Bwindi Impenetrable National Park, Uganda. PhD dissertation, University of Leipzig, Germany.

Pazol, K., \& Cords, M. (2005). Seasonal variation in feeding behavior, competition and female social relationships in a forest dwelling guenon, the blue monkey (Cercopithecus mitis stuhlmanni), in the Kakamega Forest, Kenya. Behavioral Ecology and Sociobiology, 58, 566-577. doi:10.1007/s00265-005-0953-3.

Pruetz, J. D., \& Isbell, L. A. (2000). Correlations of food distribution and patch size with agonistic interactions in female vervets (Chlorocebus aethiops) and patas monkeys (Erythrocebus patas) living in simple habitats. Behavioral Ecology and Sociobiology, 49, 38-47. doi:10.1007/s002650000272.

Pusey, A., Williams, J., \& Goodall, J. (1997). The influence of dominance rank on the reproductive success of female chimpanzees. Science, 277, 828-831. doi:10.1126/science.277.5327.828.

Range, F., \& Noë, R. (2002). Familiarity and dominance relations among female sooty mangabeys in the Taï National Park. International Journal of Primatology, 56, 137-153.

Robbins, M. M. (1996). Male-male interactions in heterosexual and all-male wild mountain gorilla groups. Ethology, 102.

Robbins, M. M. (2003). Behavioral aspects of sexual selection in mountain gorillas. In C. L. Jones (Ed.), Sexual Selection \& Reproductive Competition in Primates: New Perspectives and Directions (pp. 477-501). Norman, OK: American Society of Primatologists.

Robbins, M. M. (2007). Gorillas: Diversity in ecology and behavior. In C. J. Campbell, A. Fuentes, M. Panger, K. C. MacKinnon, \& S. Bearder (Eds.), Primates in Perspective (pp. 305-321). Oxford: Oxford University Press.

Robbins, M. M., Bermejo, M., Cipolletta, C., Magliocca, F., Parnell, R. J., \& Stokes, E. (2004). Social structure and life history patterns in western gorillas (Gorilla gorilla gorilla). American Journal of Primatology, 64, 145-159. doi:10.1002/ajp.20069.

Robbins, M. M., \& McNeilage, A. (2003). Home range and frugivory patterns of mountain gorillas in Bwindi Impenetrable National Park, Uganda. International Journal of Primatology, 24, 467-491. doi:10.1023/A:1023741328338. 
Robbins, M. M., Nkurunungi, J. B., \& McNeilage, A. (2006). Variability of the feeding ecology of eastern gorillas. In G. Hohmann, M. M. Robbins, \& C. Boesch (Eds.), Feeding Ecology in Apes and Other Primates: Ecological, Physical, and Behavioral Aspects (pp. 24 46). Cambridge, U.K.: Cambridge University Press.

Robbins, M. M., Robbins, A. M., Gerald-Steklis, N., \& Steklis, H. D. (2005). Long-term dominance relationships in female mountain gorillas: Strength, stability and determinants of rank. Behaviour, 142, 779-809. doi:10.1163/1568539054729123.

Robbins, M. M., Robbins, A. M., Gerald-Steklis, N., \& Steklis, H. D. (2007). Female reproductive success of the Virunga mountain gorillas: Comparisons with the socioecological model. Behavioral Ecology and Sociobiology, 61, 919-931. doi:10.1007/s00265-006-0321-y.

Rogers, M. E., Abernethy, K., Bermejo, M., Cipolletta, C., Doran, D., McFarland, K., et al. (2004). Western gorilla diet: A synthesis from six sites. American Journal of Primatology, 64, 173-192. doi:10.1002/ajp.20071.

Saito, C. (1996). Dominance and feeding success in female Japanese macaques, Macaca fuscata: Effects of food patch size and inter-patch distance. Animal Behaviour, 51, 967-980. doi:10.1006/ anbe.1996.0100.

Schaller, G. (1963). The Mountain Gorilla: Ecology and Behavior. Chicago: University of Chicago Press.

Schülke, O. (2003). To breed or not to breed-food competition and other factors involved in female breeding decisions in the pair-living nocturnal fork-marked lemur (Phaner furcifer). Behavioral Ecology and Sociobiology, 55, 11-21. doi:10.1007/s00265-003-0676-2.

Sicotte, P. (2001). Female mate choice in mountain gorillas. In M. M. Robbins, P. Sicotte, \& K. J. Stewart (Eds.), Mountain Gorillas: Three Decades of Research at Karisoke (pp. 59-87). Cambridge, U.K.: Cambridge University Press.

Snaith, T., \& Chapman, C. P. (2005). Towards an ecological solution to the folivore paradox: patch depletion as an indicator of within-group scramble competition in red colobus monkeys (Piliocolobus tephrosceles). Behavioral Ecology and Sociobiology, 59, 185-190. doi:10.1007/s00265-005-0023-x.

Sterck, E. H. M., \& Steenbeek, R. (1997). Female dominance relationships and food competition in the sympatric Thomas langur and long-tailed macaque. Behaviour, 134, 749-774. doi:10.1163/ $156853997 X 00052$.

Sterck, E. H. M., Watts, D. P., \& van Schaik, C. P. (1997). The evolution of female social relationships in nonhuman primates. Behavioral Ecology and Sociobiology, 41, 291-309. doi:10.1007/ s002650050390.

Stevenson, P. R., Quinones, M. J., \& Ahumada, J. A. (1998). Effects of fruit patch availability on feeding subgroup size and spacing patterns in four primate species at Tinigua National Park, Colombia. International Journal of Primatology, 19, 313-324. doi:10.1023/A:1020387700923.

Stokes, E. J. (2004). Within-group social relationships amongst females and adult males in wild western lowland gorillas (Gorilla gorilla gorilla). American Journal of Primatology, 64, 233-246. doi:10.1002/ajp.20074.

Stokes, E. J., Parnell, R. J., \& Olejniczak, C. (2003). Female dispersal and reproductive success in wild western lowland gorillas (Gorilla gorilla gorilla). Behavioral Ecology and Sociobiology, 54, 329339. doi:10.1007/s00265-003-0630-3.

Strier, K. B. (1989). Effects of patch size on feeding associations in muriquis (Brachyteles arachnoides). Folia Primatologica, 52, 70-77.

Symington, M. M. (1988). Food competition and foraging party size in the black spider monkey (Ateles panicscus chamek). Behaviour, 105, 1117-1134.

van Schaik, C. P. (1989). The ecology of social relationships amongst female primates. In V. Standon, \& R. A. Foley (Eds.), Comparative Socioecology: The Behavioural Ecology of Humans and Other Mammals (pp. 195-218). Blackwell, Oxford.

van Schaik, C. P., \& van Noordwijk, M. A. (1988). Scramble and contest in feeding competition among female long-tailed macaques (Macaca fascicularis). Behaviour, 105, 77-98. doi:10.1163/ 156853988 X00458.

Vogel, E. (2005). Rank differences in energy intake in white-faced capuchin monkeys, Cebus capucinus: The effects of contest competition. Behavioral Ecology and Sociobiology, 58, 333-344. doi:10.1007/ s00265-005-0960-4.

Watts, D. P. (1984). Composition and variability of mountain gorilla diets in the Central Virungas. American Journal of Primatology, 7, 323-356. doi:10.1002/ajp.1350070403.

Watts, D. P. (1985). Relations between group size and composition and feeding competition in mountain gorilla groups. Animal Behaviour, 33, 72-85. doi:10.1016/S0003-3472(85)80121-4.

Watts, D. P. (1990). Ecology of gorillas and its relation to female transfer in mountain gorillas. International Journal of Primatology, 11, 21-44. 
Watts, D. P. (1992). Social relationships of immigrant and resident female mountain gorillas, I. Malefemale relationships. American Journal of Primatology, 28, 159-181. doi:10.1002/ajp.1350280302.

Watts, D. P. (1994). Agonistic relationships of female mountain gorillas. Behavioral Ecology and Sociobiology, 34, 347-358. doi:10.1007/BF00197005.

Watts, D. P. (1996). Comparative socioecology of gorillas. Great Ape Societies. In W. C. McGrew, L. F. Marchant, \& T. Nishida (Eds.), Great Ape Societies (pp. 16-28). Cambridge, U.K.: Cambridge University Press.

Watts, D. P. (1998). Long term habitat use by mountain gorillas (Gorilla gorilla beringei) 1. Consistency, variation, and home range size and stability. International Journal of Primatology, 19, 651-680. doi:10.1023/A:1020324909101.

Watts, D. P. (2001). Social relationships of female mountain gorillas. In M. M. Robbins, P. Sicotte, \& K. J. Stewart (Eds.), Mountain Gorillas: Three Decades of Research at Karisoke (pp. 215-240). Cambridge, U.K.: Cambridge University Press.

Watts, D. P. (2003). Gorilla social relationships: A comparative overview. In A. B. Taylor, \& M. L. Goldsmith (Eds.), Gorilla Biology: A Multidisciplinary Perspective (pp. 302-327). Cambridge, U.K.: Cambridge University Press.

Watts, D. P., \& Pusey, A. E. (1993). Behavior of juvenile and adolescent great apes. In M. E. Pereira, \& L. A. Fairbanks (Eds.), Juvenile Primates (pp. 148-167). Oxford: Oxford University Press.

White, F. J., \& Wrangham, R. W. (1988). Feeding competition and patch size in the chimpanzee species Pan paniscus and Pan troglodytes. Behaviour, 104, 148-164. doi:10.1163/156853988X00494.

Whitten, P. L. (1983). Diet and dominance among female vervet monkeys (Cercopithecus aethiops). American Journal of Primatology, 5, 139-159. doi:10.1002/ajp.1350050205.

Wittig, R. M., \& Boesch, C. (2003). Food competition and linear dominance hierarchy among female chimpanzees of the Tai National Park. International Journal of Primatology, 24, 847-867. doi:10.1023/A:1024632923180.

Wrangham, R. W. (1980). An ecological model of female-bonded primate groups. Behaviour, 75, 262300. doi:10.1163/156853980X00447.

Yamagiwa, J., \& Kahekwa, J. (2001). Dispersal patterns, group structure, and reproductive parameters of eastern lowland gorillas at Kahuzi in the absence of infanticide. In M. M. Robbins, P. Sicotte, \& K. J. Stewart (Eds.), Mountain Gorillas: Three Decades of Research at Karisoke (pp. 89-122). Cambridge, U.K.: Cambridge University Press.

Yamagiwa, J., Kahekwa, J., \& Basabose, A. K. (2003). Intra-specific variation in social organization of gorillas: Implications for their social evolution. Primates, 44, 359-369. doi:10.1007/s10329-0030049-5.

Zucker, E. L., \& Clarke, M. R. (1998). Agonistic and affiliative relationships of adult female howlers (Alouatta palliate) in Costa Rica over a 4-year period. International Journal of Primatology, 19, 433449 . 